\title{
Mechanical Properties Prediction of Normal and High Strength Geopolymer Concrete
}

\author{
Sameh B. Tobeia ${ }^{*}$, Nada S. Assi, Narjis S. Abbas \\ Civil Engineering Dept., University of Technology-Iraq, Alsina'a Street, P.O Box 10066 Baghdad, Iraq. \\ *Corresponding author Email: 40115@uotechnology.edu.iq
}

\section{H I G H L I G H T S}

- Geopolymer concrete an alternative binder material.

- The production of GPC depended on the minerals found in materials such as fly ash.

- Predication of mechanical properties for normal and high strength GPC.

\section{A R T I C L E I N F O}

Handling editor: Wasan I. Khalil

Keywords:

Flexural strength

Geopolymer concrete

High strength

Modulus of elasticity

Splitting tensile strength

\author{
A B S T R A C T
}

The production process of cement is the main binder material in concrete usually accompanied by carbon dioxide emission. Therefore, geopolymer concrete (GPC) an alternative binder material was developed as a replacement for cement. In order to make this promising material more common in constructions and applicable for different design purposes further investigations for GPC mechanical properties were needed. This work aims to predicate the splitting tensile strength, modulus of elasticity and flexural strength for normal and high strength GPC by deriving new equations covering a wide range of compressive strength based on data available from previous work. Equations behavior along the changes in compressive strength from normal to high is adopted in comparisons as illustrated. The results show that the proposed equations, as compared with other equations established by previous works, provide a steady behavior for the various values of compressive strength especially for high strength. The coefficient of variation (COV) used as additional comparison criteria, and shows that the proposed equations provide better estimation of GPC mechanical properties.

\section{Introduction}

As the concrete became one of the most common construction materials, and due to the massive consumption of cement which is considered the main binder material in concrete, huge amounts of carbon dioxide emitted during cement manufacturing. This emission released the harmful carbon dioxide to the environment causing devastated effects. Therefore, geopolymer concrete (GPC) appeared as an alternative concrete type where cement is no more the binder material. The production of GPC basically depended on the minerals found in materials such as fly ash or ground granulated blast furnace slag. When GPC is based on fly ash, minerals like silica and aluminate are expected to be the main minerals. In order to activate the polymerization of these minerals, alkaline activator solution such as sodium silicate or sodium hydroxide is usually added, as the chemical reaction contains alkali aluminosilicate were formed, this compound act as a calcium silicon hydrate which is necessary to bind the particles of aggregate and improving the compressive strength. Several previous works investigated both chemicals and physical GPC properties, Kalaivani [1] examined the flexural strength of GPC based on fly ash. Venu and Rao [2] investigated the mechanical properties of GPC using a certain concentration of $\mathrm{NaOH}$ and studied the behavior of stress-strain curve with the strength of GPC. Sreenivasulu et al. [3] studied the GPC stress-strain characteristics using the granite fines as a partial replacement of fine aggregate. Kamalet al. [4] studied the properties and the advantages of High-Strength GPC with compressive strength of $65 \mathrm{MPa}$ and $80 \mathrm{MPa}$.Wasan et al. [5] studied the possibility of using the waste of clay brick in geopolymer concrete production. Wasan et al.[6] examined the effects of the use of ordinary Portland cement on geopolymer concrete properties. Therefore, due to the promising environmental gain coming from using GPC, further studied that investigate the mechanical properties of GPC should be done to make this innovative material more suitable for different structural purposes.

The main objective behind this work, is to examine the prediction of high strength GPC mechanical properties in the light of the available equations from previous works, and establishing new equations to reach this goal. 


\section{Mechanical Properties for Cement Concrete}

Whatever the type of concrete; normal strength concrete, high strength concrete, high performance concrete, geopolymer concrete or any other type, the knowledge of concrete mechanical properties are still very important to achieve the design requirements as new types of concrete appeared.

\subsection{Splitting tensile strength}

Basically, the splitting tensile strength depended on the compressive strength of concrete $\left(\mathrm{f}_{\mathrm{c}}^{\prime}\right)$; therefore, a basic model Eq. (1) based on $\left(\mathrm{f}_{\mathrm{c}}^{\prime}\right)$ and non-dimensional coefficients usually found by regression analysis were adopted and used over the years by several provisions (codes) as well as researchers.

$$
\mathrm{f}_{\mathrm{spt}}=\mathrm{a} \cdot\left(\mathrm{f}_{\mathrm{c}}^{\prime}\right)^{\mathrm{b}}
$$

Where, $\mathrm{f}_{\mathrm{spt}}=$ splitting tensile strength $(\mathrm{MPa})$;

$\mathrm{f}_{\mathrm{c}}^{\prime}=$ compressive strength $(\mathrm{MPa})$;

$\mathrm{a}$ and $\mathrm{b}=$ non-dimensional coefficients.

Eq. (1) have been adopted using different coefficients values by codes and researchers, as detailed in Table (1):

\subsection{Modulus of elasticity}

Different types of concrete usually consist of various materials differ in density and modulus of elasticity, therefore static modulus of elasticity for concrete should be considered. The formula in Eq. (2) is a basic form used to establish the modulus of elasticity based on $\left(\mathrm{f}_{\mathrm{c}}^{\prime}\right)$ and unit weight of concrete $(\gamma)$ as well as the non-dimensional coefficients. Table $(2)$ lists several previous formulas derived in depending on Eq. (2).

$$
E_{c}=c \cdot\left(f_{c}^{\prime}\right)^{d}
$$

Where $\mathrm{Ec}=$ modulus of elasticity $(\mathrm{MPa}) ; \gamma=$ unit weight of concrete;

$\mathrm{c}, \mathrm{d}$ and $\mathrm{e}=$ non-dimensional coefficients, found by regression analysis

\subsection{Flexural strength}

The flexural strength represented by the modulus of rupture for concrete can be predicted by Eq. (3), based on ( $\left.f_{\mathrm{c}}^{\prime}\right)$ and the non-dimensional coefficients. Table (3) lists several previous formulas used to predict the modulus of rupture.

$$
f_{r}=f \cdot\left(f_{c}^{\prime}\right)^{g}
$$

Where, $\mathrm{f}_{\mathrm{r}}=$ modulus of rupture $(\mathrm{MPa})$;

$\mathrm{f}$ and $\mathrm{g}=$ non-dimensional coefficients, found by regression analysis.

Table 1: Available Splitting tensile strength equations

\begin{tabular}{cccc}
\hline Code/Researcher & $\mathbf{a}$ & $\left(\mathbf{f}_{\mathbf{c}}^{\prime}\right)^{\mathbf{b}}$ & $\mathbf{f}_{\mathbf{s p t}}(\mathbf{M P a})$ \\
\hline ACI-318M-14[7] & 0.56 & $\left(\mathrm{f}_{\mathrm{c}}^{\prime}\right)^{0.5}$ & $0.56\left(\mathrm{f}_{\mathrm{c}}^{\prime}\right)^{0.5}$ \\
CEB-90[8] & 0.33 & $\left(\mathrm{f}_{\mathrm{c}}^{\prime}\right)^{0.66}$ & $0.33\left(\mathrm{f}_{\mathrm{c}}^{\prime}\right)^{0.66}$ \\
Lavanya and Jegan[9] & 0.249 & $\left(\mathrm{f}_{\mathrm{c}}^{\prime}\right)^{0.772}$ & $0.249\left(\mathrm{f}_{\mathrm{c}}^{\prime}\right)^{0.772}$ \\
Arioglu et al.[10] & 0.387 & $\left(\mathrm{f}_{\mathrm{c}}^{\prime}\right)^{0.63}$ & $0.387\left(\mathrm{f}_{\mathrm{c}}^{\prime}\right)^{0.63}$ \\
\hline
\end{tabular}

Table 2: Available modulus of elasticity equations

\begin{tabular}{ccccc}
\hline Code/Researcher & $\mathbf{c}$ & $\left(\mathbf{f}_{\mathrm{c}}^{\prime}\right)^{\mathbf{d}}$ & $\boldsymbol{\gamma}^{\mathbf{e}}$ & $\mathbf{E}_{\mathbf{c}}$ \\
\hline ACI-318M-14[7] & 4700 & $\left(\mathrm{f}_{\mathrm{c}}^{\prime}\right)^{0.5}$ & - & $4700\left(\mathrm{f}_{\mathrm{c}}^{\prime}\right)^{0.5}, \mathrm{Ec} \mathrm{in} \mathrm{MPa}$ \\
CEB-90[8] & 10000 & $\left(\mathrm{f}_{\mathrm{c}}^{\prime}+8\right)^{(1 / 3)}$ & - & $10000\left(\mathrm{f}_{\mathrm{c}}^{\prime}+8\right)^{(1 / 3)}, \mathrm{Ec}$ in MPa \\
AS3600[11] & - & $\left(\mathrm{f}_{\mathrm{c}}^{\prime}\right)^{0.5}$ & $\gamma^{1.5}$ & $\gamma^{1.5}\left(0.024\left(\mathrm{f}_{\mathrm{c}}^{\prime}\right)^{0.5}+0.12\right), \mathrm{E}_{\mathrm{c}}$ in MPa \\
Sreenivasuluetet al.[3] & 0.186 & $\left(\mathrm{f}_{\mathrm{c}}^{\prime}\right)^{0.5}$ & $\gamma^{0.42}$ & $0.186 \gamma^{0.42} \cdot\left(\mathrm{f}_{\mathrm{c}}^{\prime}\right)^{0.5}, \mathrm{Ec} \mathrm{in} \mathrm{GPa}$ \\
\hline
\end{tabular}

Table 3: Available modulus of rupture equations

\begin{tabular}{cccc}
\hline Code & $\mathbf{f}$ & $\left(\mathbf{f}_{\mathrm{c}}^{\prime}\right)^{\mathbf{g}}$ & $\mathbf{f}_{\mathbf{r}}(\mathbf{M P a})$ \\
\hline ACI-318M-14[7] & 0.62 & $\left(\mathrm{f}_{\mathrm{c}}^{\prime}\right)^{0.5}$ & $0.62\left(\mathrm{f}_{\mathrm{c}}^{\prime}\right)^{0.5}$ \\
AS3600[11] & 0.6 & $\left(\mathrm{f}_{\mathrm{c}}^{\prime}\right)^{0.5}$ & $0.6\left(\mathrm{f}_{\mathrm{c}}^{\prime}\right)^{0.5}$ \\
\hline
\end{tabular}




\section{Mechanical Properties Estimation for Geopolymer Concrete (GPC)}

The needs to prove that the of GPC is able to be a sufficient alternative for cement concrete is obvious, for this purpose one of the goals that needed to be reached is the ability to produce High-Strength GPC. Therefore, additional attention should be paid to get a better understanding for the high levels of compressive strength in GPC. Thus, the extended investigations for the mechanical properties of High-Strength GPC were needed.

In this work, based on data provided by pervious works, the mechanical properties of GPC were revisited, in which new formulas are proposed for estimating splitting tensile strength, modulus of elasticity and flexural strength in order to be more appropriate for both normal and high compressive strength.

In order to establish the proposed equation of the splitting tensile strength Eq. (4), the regression analysis was applied on the available data [2,12-21], in which 102 specimens with compressive strength ranging from 18.66 MPa to $89 \mathrm{MPa}$ were examined. The basic model in Eq. (1) is adopted and the regression analysis was intended to obtain the non-dimensional coefficients ( $a$ and $b)$.

$$
\mathrm{f}_{\mathrm{spt}}=0.65\left(\mathrm{f}_{\mathrm{c}}^{\prime}\right)^{0.44}
$$

The proposed equation (Eq. (4)) is found to be more appropriate for both normal and high compressive strength, with a steady behavior along with different values of $\left(\mathrm{f}_{\mathrm{c}}^{\prime}\right)$.

To establish a suitable formula used in estimating GPCmodulus of elasticity, the regression analysis was applied on 148 specimens with compressive strength of $25 \mathrm{MPa}$ to $91.5 \mathrm{MPa}$ provided by previous works $[2,3,12,13,16,17,20-26]$, based on Eq. (2) the non-dimensional coefficients (c,d and e) are found to be $12.33,0.4$ and 0.8 respectively. The proposed equation Eq. (5) established to be more applicable for both normal and high strength concrete strength.

$$
E_{c}=12.33\left(f_{c}^{\prime}\right)^{0.4} \cdot \gamma^{0.8}
$$

Eq. (6) is proposed for modulus of rupture based on 109 specimens with compressive strength ranging from $18.66 \mathrm{MPa}$ to 80.37 MPa provided by previous works $[2,13,16-21,25,26]$ by applying the regression analysis.

$$
f_{r}=0.73\left(f_{c}^{\prime}\right)^{0.41}+0.988
$$

\section{Results Analysis}

The results of GPC mechanical properties established by applying the equations proposed in this work and the equations provided by previous researchers and codes on the available data are compared by adopting the coefficient of variation (COV). The comparisons were based on the ratio of the experimental to the calculated results, in which the calculated results were found by applying the studied approaches in this work. Table (4) summarized the comparisons results for the splitting tensile

\begin{tabular}{|c|c|c|c|}
\hline \multicolumn{4}{|c|}{ Splitting tensile strength $\left(\mathrm{f}_{\mathrm{spt}}\right)(\mathrm{MPa})$} \\
\hline Equation & $\begin{array}{c}\text { Average of } \\
\left(f_{\text {spt }}\right) \text { test } /\left(f_{\text {spp }}\right) \text { calculated }\end{array}$ & $\begin{array}{c}\frac{\text { Min. }}{\text { Max. }} \text { of } \\
\left(f_{\text {sp }}\right) \text { test } /\left(f_{\text {spt }}\right) \text { calculated }\end{array}$ & $\underset{\%}{C O V}$ \\
\hline ACI-318M-14[7] & 1.086 & 0.388 & 23.167 \\
\hline CEB-90[8] & 1.028 & 0.376 & 24.396 \\
\hline Lavanya and Jegan[9] & 0.907 & 0.352 & 25.822 \\
\hline Arioglu et al.[10] & 0.978 & 0.383 & 24.087 \\
\hline Proposed equation, Eq.(4) & 1.165 & 0.388 & 22.992 \\
\hline \multicolumn{4}{|c|}{ Modulus of elasticity $\left(E_{c}\right)(M P a)$} \\
\hline Equation & $\begin{array}{c}\text { Average of } \\
\left(E_{c}\right) \text { test } /\left(E_{c}\right) \text { calculated }\end{array}$ & $\begin{array}{c}\frac{\text { Min. }}{\text { Max. of }} \\
\left(E_{c}\right) \text { test } /\left(E_{c}\right) \text { calculated }\end{array}$ & $\underset{\%}{C O V}$ \\
\hline ACI-318M-14[7] & 1.016 & 0.252 & 20.118 \\
\hline CEB-90[8] & 0.851 & 0.217 & 20.316 \\
\hline AS 3600[11] & 0.917 & 0.218 & 20.090 \\
\hline Sreenivasuluet et al.[3] & 0.963 & 0.252 & 20.075 \\
\hline Proposed equation, Eq.(5) & 1.089 & 0.236 & 19.841 \\
\hline \multicolumn{4}{|c|}{ Modulus of rupture $\left(\mathrm{f}_{\mathrm{r}}\right)$ (MPa) } \\
\hline Equation & $\begin{array}{c}\text { Average of } \\
\left(f_{r}\right) \text { test } /\left(f_{r}\right) \text { calculated }\end{array}$ & $\begin{array}{c}\frac{\text { Min. }}{\text { Max. }} \text { of } \\
\left(f_{r}\right) \text { test } /\left(f_{r}\right) \text { calculated }\end{array}$ & $\underset{\%}{C O V}$ \\
\hline ACI-318M-14[7] & 1.334 & 0.355 & 20.030 \\
\hline AS 3600[11] & 1.379 & 0.355 & 19.476 \\
\hline Proposed equation, Eq.(6) & 1.205 & 0.309 & 19.410 \\
\hline
\end{tabular}
strength, modulus of elasticity and flexural strength for GPC.

Table 4: Mechanical properties estimation of GPC 


\section{Discussion}

In this work, comparisons were made based on ratio of the experimental to the predicted values. The results obtained from the proposed equation (Eq.(4)) that used to estimate the splitting tensile strength show a steady behavior along with the increase in compressive strength providing a suitable estimation for splitting tensile especially for high-strength GPC, while the revisited equations tend to be unconservative with the increasing in GPC compressive strength as illustrated in Fig.(1), the unconservative behavior can be led to uncertain estimation with higher values of compressive strength. The COV obtained from applying Eq. (4) provide the lowest value as results summarized in Table (4).

Eq.(5) and Eq.(6) which proposed to predicted the modulus of elasticity and the flexural strength for GPC respectively shows similar behavior to Eq.(4), along with the higher values of compressive strength. Where, almost a steady behavior was established due to applying the proposed equations for high strength GPC. In the other hand, some of the revisited equations show unconservative behavior others tend to be more conservative, in both cases insufficient estimation for modulus of elasticity and flexural strength can be provided with higher values of compressive strength, see Fig.(2) and Fig.(3).

Several of the revisited equations examined in this work tend to overestimated suffer from a decent in the estimating values, for splitting tensile strength estimation, this behavior found to be concentrated in the high strength reign. Similarly the prediction of modulus of rupture can be described. While, modulus of elasticity behavior changed from conservative to unconservative from method to another.

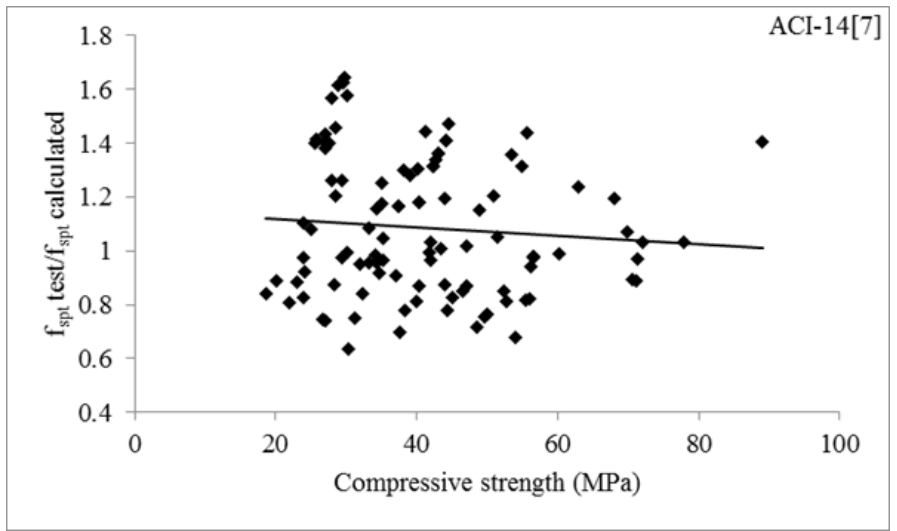

a) ACI $318 \mathrm{M}-14[7]$

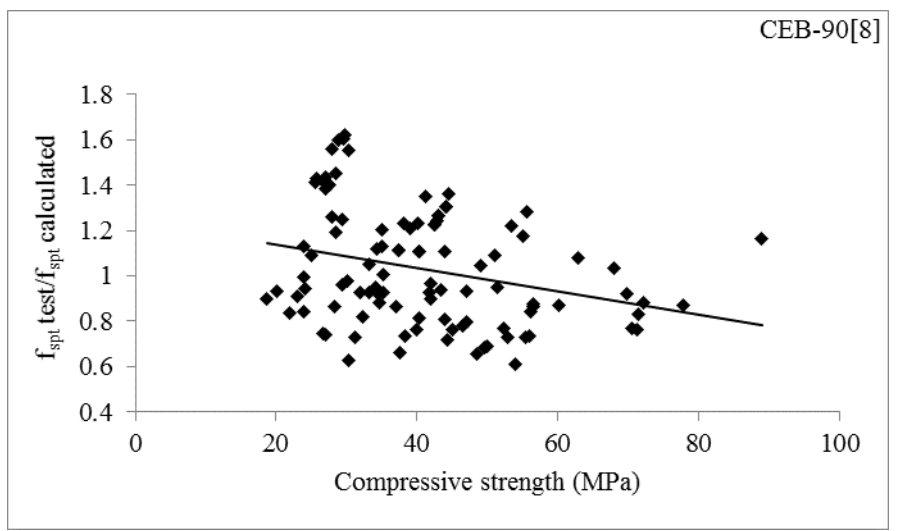

b) CEB-90[8]

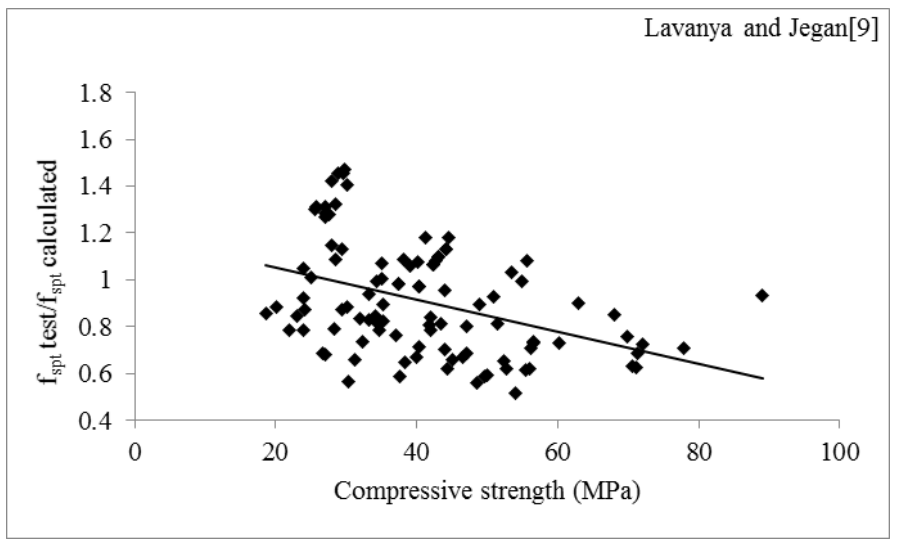

c) Lavanya and Jegan equation [9] 


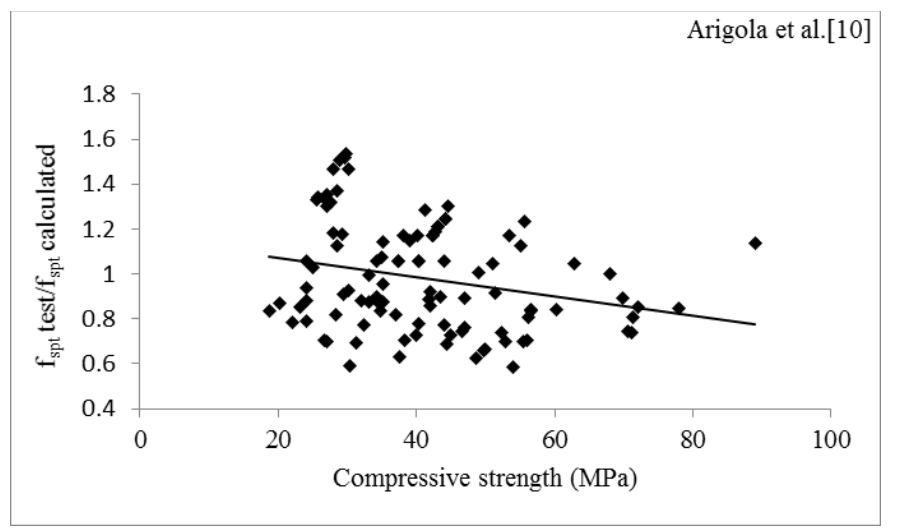

d) Arigola et al.[10]

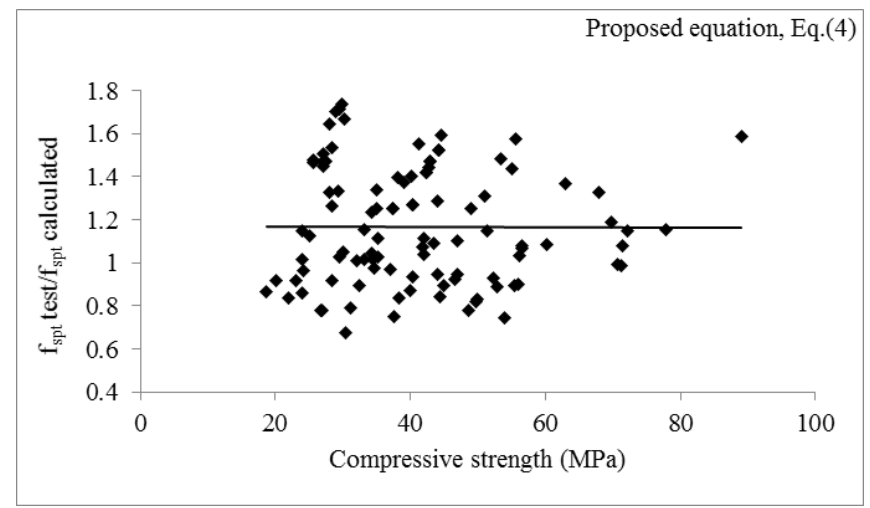

e) Proposed equation, Eq.(4)

Figure 1: Splitting tensile strength-compressive strength relationship

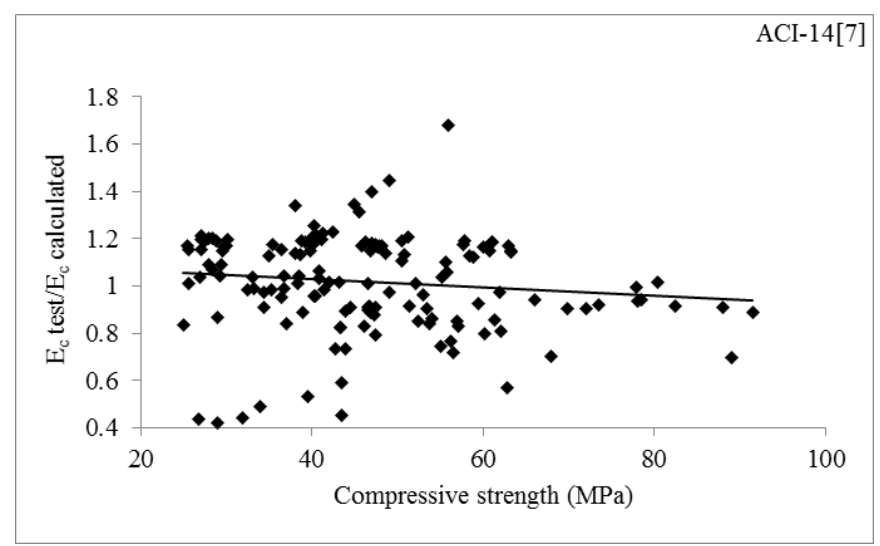

a) ACI $318 \mathrm{M}-14[7]$

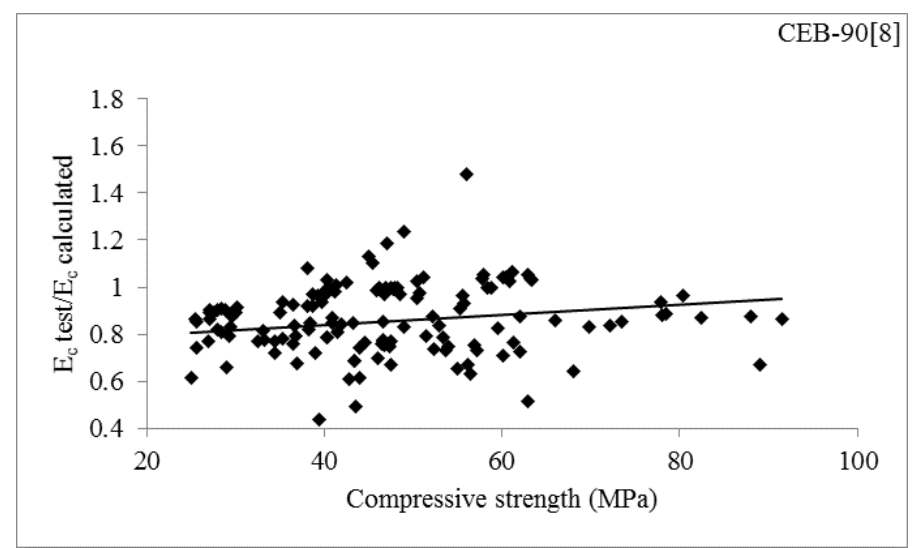

b) CEB-90[8] 


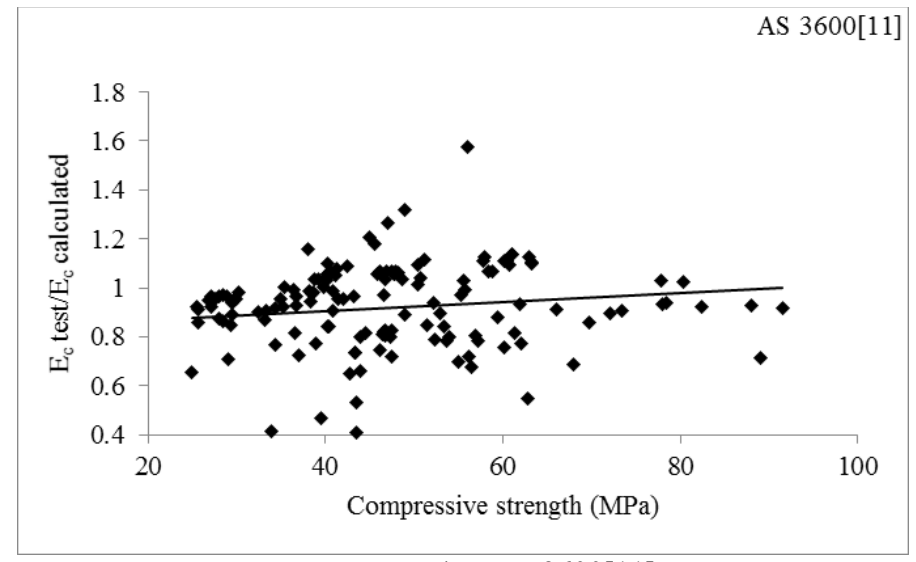

c) AS 3600[11]

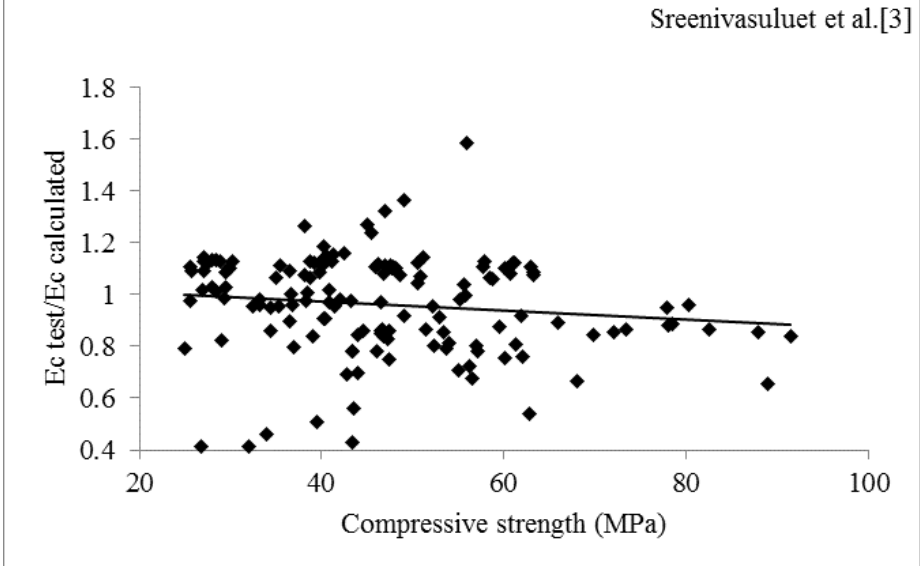

d) Sreenivasuluet et al.[3]

Proposed equation, Eq.5

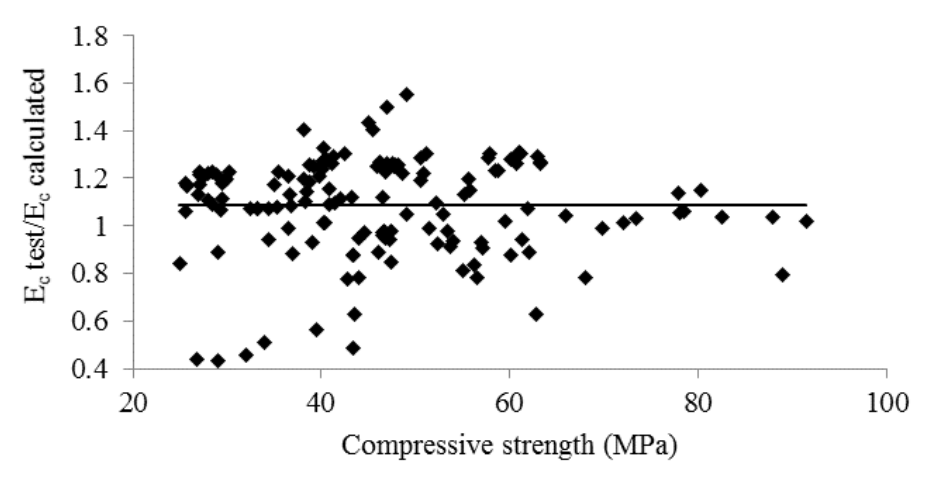

e) Proposed equation, Eq. (5)

Figure 2: Modulus of elasticity-compressive strength relationship

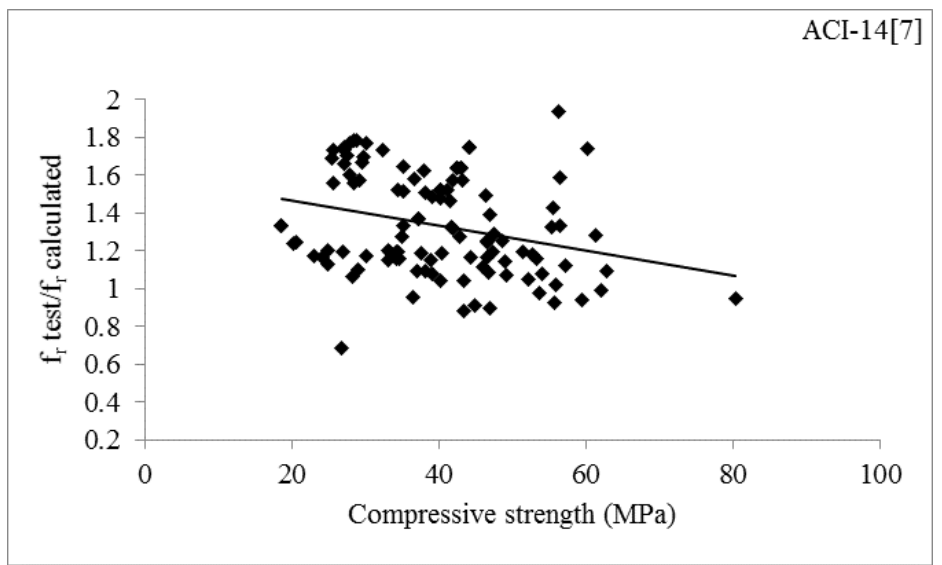

a) ACI $318 \mathrm{M}-14[7]$ 


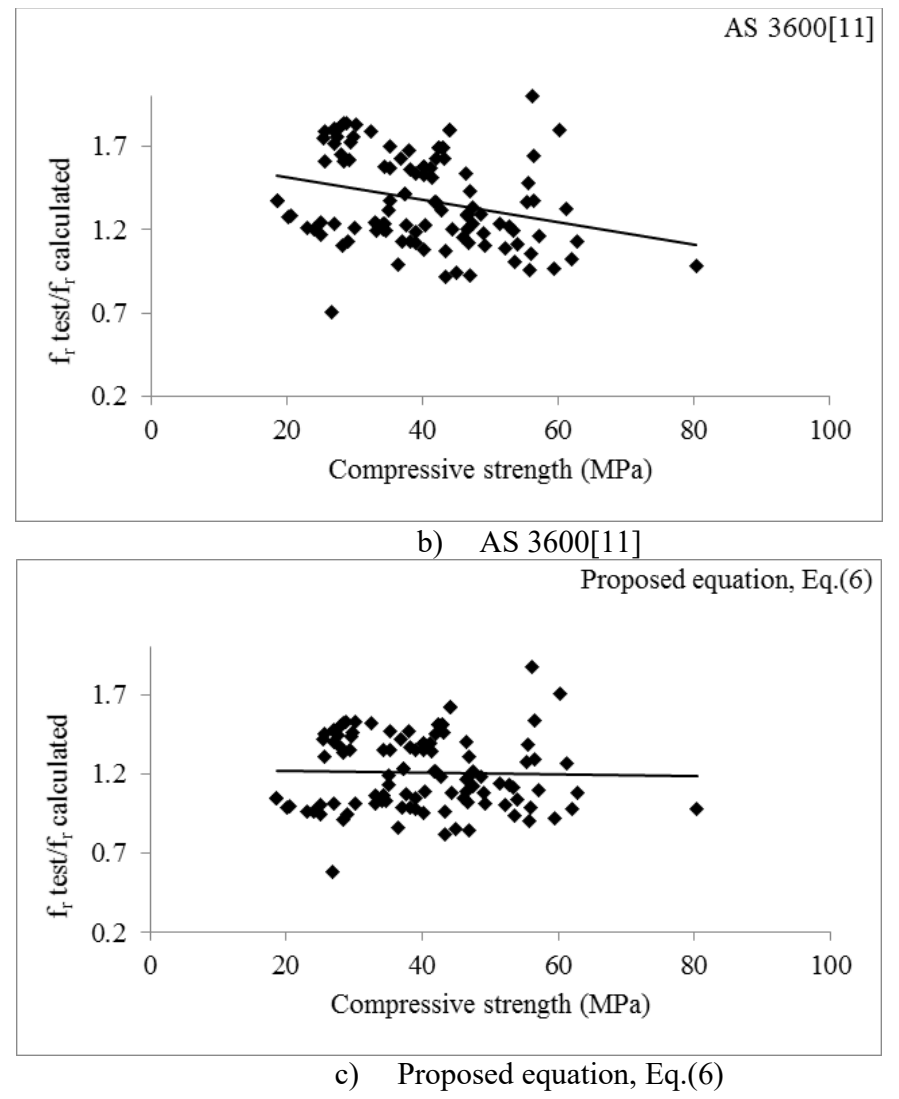

Figure 3: Flexural strength - compressive strength relationship

\section{Conclusions}

Several conclusions were found based on the results of the equations examined and proposed in this work.

1. Whilst the revisited equations established for cement concrete, most of these equations tend to behave conservatively with higher values of GPC compressive strength.

2. In spite of the close COV values, the conservative or unconservative behavior along with variation of GPC compressive strength as illustrated, provide a good indicator for the reliability of mechanical properties estimated by these equations.

3. The equations proposed in this work, may provide a better estimation for GPC mechanical properties with a steady response for the variation in compressive strength especially for higher values of compressive strength.

4. The prediction of splitting tensile strength, modulus of elasticity and modulus of rupture for GPC can be based on the existing equations for normal compressive strength, even most of these formulas were derived at first place for conventional concrete.

\section{Author contribution}

All authors contributed equally to this work.

\section{Funding}

This research received no specific grant from any funding agency in the public, commercial, or not-for-profit sectors.

Data availability statement

The data that support the findings of this study are available on request from the corresponding author.

\section{Conflicts of interest}

The authors declare that there is no conflict of interest.

\section{References}

[1] M.Kalaivani, Experimental investigation for flexural strength of fly ash concrete with addition of alkaline activater, ARPN Journal of Engineering and Applied Sciences, 10(2015) 4838-4841. https://doi.org/10.1016/j.conbuildmat.2015.12.033

[2] M. Venuand T. D.Rao, An experimental investigation of the stress-strain behavior of geopolymer concrete, SJCE., 26(2018) 30-34. https://doi.org/10.2478/sjce-2018-0011 
[3] S.Chitralaa, G. J. Jadaproluband S.Chundupallia, Study and predicting the stress-strain characteristics of geopolymer concrete under compression, Case Stud. Constr. Mater., 8(2018) 172-192. https://doi.org/10.1016/j.cscm.2018.01.010

[4] K.Neupane, D. Chalmers and P.Kidd, High-Strength geopolymer concrete- properties, advantages and challenges, Advances in Materials. 7(2018) 15-25. https://doi.org/10.11648/j.am.20180702.11

[5] W. I. Khalil, Q. J. Frayyeh, and M. F. Ahmed, Characteristics of Eco-friendly Metakaolin Based Geopolymer Concrete Pavement Bricks, Eng. Technol. J., 38(2020) 1705-1716. https://doi.org/10.30684/etj.v38i11A.1699

[6] W. I. Khalil1, Q. J. Frayyeh, H. T. Abed, Effect of Ordinary Portland Cement on Some Properties of Pervious Geopolymer Concrete, Eng. Technol. J., 39(2021) 668-674. https://doi.org/10.30684/etj.v39i4a.1793

[7] ACI Committee 318, Building Code Requirements for Structural Concrete (ACI 318M-14) and Commentary, American Concrete Institute, Farmington Hills, Michigan, emotion,503, 2014.

[8] CEB-FIP Model Code 90, CEB Bulletin No. 213/214, 1993.

[9] G. Lavanyaand J.Jegan, Evaluation of relationship between split tensile strength and compressive strength for geopolymer concrete of varying grades and molarity, Int. J. Appl. Eng., 10(2015)35523-35527.

[10] N.Arioglu, Z. C. Girginand E.Arioglu, Evaluation of Ratio between Splitting Tensile Strength and Compressive Strength for Concretes up to $120 \mathrm{MPa}$ and its Application in Strength Criterion, ACI Mater. J., 103(2006)18-24.

[11] Australian Standard for Concrete Structures. AS3600, North Sydney, Australia, 1994.

[12] Z.Pan, J. G. Sanjayanand B. V.Rangan, Fracture properties of geopolymer paste and concrete, Mag. Concr. Res. , (2011) 763-771. https://doi.org/10.1680/macr.2011.63.10.763

[13] M. Olivia and H.Nikraz, Properties of fly ash geopolymer concrete designed by Taguchi method, Mater. Des., 36(2012)191-198. https://doi.org/10.1016/j.matdes.2011.10.036

[14] P. S.Deb, P. Nathand P. K.Sarker, The effects of ground granulated blast-furnace slag blending with fly ash and activator content on the workability and strength properties of geopolymer concrete cured at ambient temperature , Mater. Des., 62 (2014)32-39. https://doi.org/10.1016/j.matdes.2014.05.001

[15] K. Ramujeeand M.PothaRaju, Mechanical Properties of Geopolymer Concrete Composites , 5th International Conference of Materials Processing and Characterization (ICMPC 2016), Materials Today: Proceedings , 4(2017) 2937-2945.

[16] B. Joseph and G.Mathew, Influence of aggregate content on the behavior of fly ash based geopolymer concrete , Sci. Iran., A, 19(2012) 1188-1194. https://doi.org/10.1016/j.scient.2012.07.006

[17] V.Bhikshma, M. K. Reddy and T. S.Rao, An experimental investigation on properties of geopolymer concrete (no cement concrete), Asian J. Civ. Eng., 13(2012)841-853.

[18] D.B. Raijiwalaand H. S.Patil, Geopolymer concrete: a concrete of next decade, Journal of Engineering Research and Studies, II(2011)19-25.

[19] P. S.Deb, P. Nathand P. K.Sarker, Strength and permeation properties of slag blended fly ash based geopolymer concrete , Adv. Mat. Res., 651(2013) 168-173. https://doi.org/10.4028/www.scientific.net/AMR.651.168

[20] M.Albitar, P.Visintin, M. S.Mohamed Ali, and M.Drechsler, Assessing behaviour of fresh and hardened geopolymer concrete mixed with class-f fly ash , KSCE J. Civ. Eng., 19(2015)1445-1455. https://doi.org/10.1007/s12205-014-1254-Z

[21] J. Aldredand J.Day, Is geopolymer concrete a suitable alternative to traditional concrete? , 37th Conference on Our World in Concrete and Structures, August, (2012) 29-31

[22] D.Hardjito, S. E.Wallah, D. M.Sumajouw, and V.Rangan, Fly ash-based geopolymer concrete , Aust. J. Struct. Eng., 6(2005) 1-9. https://doi.org/10.1080/13287982.2005.11464946

[23] K.Neupane, Investigation on modulus of elasticity of powder-activated geopolymer concrete , Int. J. Struct. Eng., 7(2016)262-278. http://dx.doi.org/10.1504/IJSTRUCTE.2016.077720

[24] A.Fernandez-Jimenez, A. Palomoand C.Lopez-Hombrados, Engineering properties of alkali-activated fly ash , ACI Mater. J., 103(2006)106-112. http://dx.doi.org/10.14359/15261

[25] R.Prakash, Mechanical Properties and Flexural Performance of Geopolymer Concrete , International Research Journal of Engineering and Technology (IRJET), 4(2017) 5720-5724.

[26] P. Nathand P. K.Sarker, Flexural strength and elastic modulus 1 of ambient-cured blended low calcium fly ash geopolymer concrete, Constr. Build. Mater., 130(2017) 22-31. http://dx.doi.org/10.1016/j.conbuildmat.2016.11.034 